\title{
'Pedagogia das Possibilidades': é possível um currículo para a diversidade nas escolas brasileiras?
}

Windyz B. Ferreira

Doutora em Educação pela University of Manchester (Inglaterra) e Professora do Centro de Educação da Universidade Federal da Paraíba

E-mail: windyzferreira@ hotmail.com
Resumo: É possível um currículo para a diversidade e que seja responsivo aos direitos de todos/as à educação? A fim de responder a essa pergunta, abordo historicamente a desigualdade social, caracterizando as crenças que legitimam a vitimização do outro/a 'diferente'. Dados revelam a desigualdade educacional entre grupos na América Latina e no Brasil. Resgato a história do currículo escolar indicando um campo minado, com mais dissensos do que consensos. Conceituo diversidade e discuto sua relação com o conceito de diferença, a fim de prevenir sua deturpação: transformar diversidade em diferença individual - marca identitária que gera exclusão. Finalmente, apresento reflexão sobre um currículo para a diversidade e para o direito de todos/as os estudantes por meio da Pedagogia das Possibilidades. Espero contribuir para o debate que visa romper com a cultura vigente de valorização das impossibilidades em detrimento da valorização das boas práticas pedagógicas.

Palavras-chave: Currículo. Diversidade. Diferença. Direitos humanos. Pedagogia das Possibilidades. 


\section{INTRODUÇÃO}

Abordar o tema currículo no contexto do debate da política de inclusão dentro do qual hoje ${ }^{1}$ o sistema educacional brasileiro está imerso constitui, ao mesmo tempo, uma necessidade e um desafio. Uma necessidade porque, inevitavelmente, esse tema implica a discussão sobre o conceito de diversidade humana e de respeito às diferenças individuais em uma sociedade que tem uma história de exclusão educacional de grupos vulneráveis. Um desafio porque este debate insere-se em um contexto educacional de construção de escolas que não foram pensadas para serem 'escolas para todos', mas escolas para poucos, ou seja, para os filhos e filhas das classes sociais privilegiadas econômica, política e culturalmente. Pensar o currículo, portanto, implica problematizá-lo, e problematizá-lo significa “definir as condições nas quais os seres humanos problematizam o que são, o que fazem e o mundo em que vivem" (FOUCAULT, 1990, p. 10).

Assim, este artigo se propõe a responder à questão: É possível um currículo para a diversidade e que seja responsivo aos direitos de todos/as à educação? Para tratar da possibilidade de um currículo para a diversidade em um contexto de exclusão e inclusão educacional de grupos vulneráveis, pareceme conveniente iniciar o mesmo trazendo algumas questões que provocam nossas concepções e problematizam esta reflexão. Convido-as/os, portanto, a ler as perguntas a seguir procurando refletir sobre elas com base em sua experiência educacional, percepções e concepção de mundo e de vida de relação, assim como de formação humana para a sociedade contemporânea que está imersa na globalização, tecnologias, comunicação e informações rápidas. Você considera que:

- o sistema de cotas (no mercado de trabalho e para a entrada na universidade) para estudantes de escolas públicas, afrodescendentes e pessoas com deficiência é uma medida apropriada para garantir oportunidades mais igualitárias ou se trata de uma medida injusta para com os estudantes que estão mais bem preparados para serem aprovados?

- um homem possui mais qualificações para ser motorista de ônibus ou de táxi do que uma mulher, tendo em vista os riscos envolvidos nessas atividades?

- um jovem negro pode ser entendido como uma pessoa com potencial maior para se tornar um problema social do que um jovem branco?

Ano de 2014. 
- uma pessoa com deficiência aprende menos do que uma pessoa sem deficiência e por isso deve ser segregada em escolas especiais?

Embora não imediatamente perceptível, essas questões têm a ver com o debate sobre currículo e diversidade, e direitos humanos, como vou argumentar neste artigo, porque subjacente a esses conceitos está contida uma concepção de mundo, de formação humana e de compreensão das relações sociais. Dependendo de suas respostas às perguntas provocadoras, é possível identificar o seu ‘mapa de mundo e sociedade’, o qual circunscreve sua concepção de formação humana, que tanto pode evidenciar respeito à diversidade ou, em oposição, valorizar a hierarquização entre grupos sociais baseada em relações de poder, assim como de crenças enraizadas na cultura dominante sobre as diferenças entre seres humanos, crenças essas criadas e perpetuadas para mantê-los fora dos círculos de poder.

Neste artigo, portanto, primeiro abordo a desigualdade social numa perspectiva histórica a fim de delinear como a desigualdade penetrou na cultura contemporânea e determinou crenças que legitimam a vitimização do outro, "que acreditamos ser diferente de nós" com base em sua diferença (SKLIAR, 2006; FERREIRA, 2004). Apresento dados que revelam a grave desigualdade educacional entre grupos que afeta a América Latina e o Brasil, e resgato sucintamente a história do currículo escolar procurando mostrar como este constitui historicamente e ainda um campo minado, com mais dissensos do que consensos teóricos e metodológicos. Na segunda seção, conceituo diversidade e discuto sua relação direta com o conceito de diferença. Enfatizo a importância da definição deste conceito como forma de prevenir sua deturpação ao transformar diversidade em diferença individual, em marca identitária (SILVA et al, 2000) que está na base do preconceito, da discriminação e da exclusão. Finalmente, apresento uma reflexão sobre um currículo para a diversidade e para o direito de todos/as os estudantes por meio da instituição de uma pedagogia que denomino Pedagogia das Possibilidades. Com este artigo espero contribuir para romper com a cultura vigente no sistema educacional de valorização das impossibilidades em detrimento da valorização das boas práticas pedagógicas e dos esforços realizados por educadores/as no Brasil no enfrentamento das impossibilidades com as quais convivem cotidianamente no exercício da docência. 
Na sociedade humana, as desigualdades sociais baseadas nas percepções das diferentes características das pessoas sempre existiram (GIDDENS, 1993). Todavia, após a Revolução Industrial, o fenômeno da desigualdade entre grupos sociais se expande e consolida a concepção da diferença como desigualdade baseada no status socioeconômico de cada ser humano, de acordo com sua origem ou 'seu berço'. Assim, uma criança que nasce em uma família rica e privilegiada terá maior vantagem social e oportunidades para ser bem-sucedida na vida adulta do que uma que nasce em uma família de baixa renda da periferia (DELORS, 2000; RIVERO, 2000; REICH, 1997; GIDDENS, 1993). Um bom exemplo dessa desigualdade historicamente naturalizada diz respeito às relações de gênero, como argumenta Carvalho et al. (2009, p. 11),

Com base nas diferenças biológicas entre mulheres e homens organizou-se uma divisão social do trabalho (reprodutivo/produtivo) e se construíram concepções de feminilidade e de masculinidade que, ao longo da história, têm sido usadas, em diferentes culturas, para justificar a inferiorização, a submissão e a opressão de mulheres. A maior valorização social dos atributos culturalmente considerados masculinos e a consequente desvalorização daqueles considerados femininos têm conferido privilégios aos homens, sobretudo aos homens heterossexuais, brancos, cristãos, de classe alta e média, legitimando hierarquias e excluindo as mulheres das esferas de poder.

Com base nesta citação, pode-se depreender que diferenças biológicas, de competências individuais ou status socioeconômico diretamente determinam a relação de dominação de um grupo em relação ao outro considerado 'inferior'. Assim, a pessoa com deficiência, o negro em uma sociedade cuja maioria é branca, o indígena ou o cigano vivendo deslocados de suas etnias, o imigrante, a pessoa com orientação sexual diferente da heterossexualidade, a pessoa pobre ou com qualquer outra característica distinta do que a cultura valoriza como atributos aceitos e socialmente valorizados vivem continuamente expostos à vitimização por discriminação e preconceitos, à falta de oportunidades e limites de acesso aos bens comuns. Embora violadora dos direitos dessas pessoas, a vitimização, com frequência, é considerada (e sentida como) legítima pela sociedade porque se acredita que essas pessoas fogem ao padrão, desviam-se do que é considerado 'normal'.

A desigualdade social que caracteriza as sociedades industrializadas e estratificadas possui claramente "níveis definidos ou strata onde grupos inteiros são elencados em uma hierarquia, mais ou menos constante, de poder e privilégios" (TAYLOR et al. 1997, p. 2-6). Talvez o maior impacto da estratificação da sociedade humana seja o fato de que um status privilegiado 
empodera alguns poucos em detrimento de muitos grupos em situação de desvantagem social. Isso significa que a elite, com maior frequência, vai ter acesso a diferentes formas de privilégio, definidos por Bilton² (1987 apud TAYLOR et al. 1997, p. 27) como os 'três 's': privilégio econômico, prestígio social e poder político (FERREIRA, 2001).

A América Latina constitui um exemplo representativo da desigualdade entre grupos porque é considerada a região mais iníqua do mundo (CASASSUS, 2007), como os dados a seguir evidenciam. Nesse continente predomina a desigualdade caracterizada por altos índices de pobreza e injustiça social: “por volta de 1999, só 5\% da população ganhava um quarto do total da renda, e $10 \%$ ganhavam $40 \%$. Em termos comparativos, esta porcentagem é similar à da África, salvo que no continente africano os níveis de renda per capita são a metade da América Latina” (CASASSUS, 2007, p. 37). No Brasil, a desigualdade se manifesta de forma contundente no campo da educação quando o foco é o acesso ao número de anos de estudo (ou escolarização) entre os jovens mais ricos e os mais pobres, com 25 anos de idade: enquanto os $10 \%$ mais ricos têm 10,5 anos de estudos (escolarização), os 10\% mais pobres tem apenas dois anos de estudo (CASASSUS, 2007, p. 39).

O reflexo de tal desigualdade entre grupos sociais está nitidamente visível na história da educação, que mostra como as escolas foram pensadas e desenhadas para um pequeno grupo de privilegiados social, econômica, política e culturalmente (RIVERO, 2000; DELORS, 2000; REICH, 1997). Ou seja, sua estrutura, funcionamento, metodologias de ensino e currículo, principalmente, ao longo de séculos asseguraram a perpetuação da desigualdade social.

A palavra currículo tem origem na palavra 'curriculum' em latim, que, etimologicamente, quer dizer pista de corrida. Assim, podemos dizer que 'no curso desta corrida que éo currículo acabamos por nos tornar o que somos' (SILVA, 1999, p. 15). O currículo, portanto, é composto, organizado e construído com conteúdos que vão desempenhar um papel determinante sobre como pensamos, agimos, em que acreditamos ou desacreditamos, $o$ que defendemos, etc. Isto é o mesmo que dizer que os conteúdos curriculares refletem os contextos históricos e sociais de cada tempo. Quando os tempos mudam, mudam também as concepções de currículo e seus conteúdos. Ao abordar o conceito de currículo, então, devemos entender que o que se ensina nas escolas - os conteúdos curriculares - reflete o tipo de pessoa que se quer formar para cada sociedade. Assim cada tempo tem seu discurso sobre o currículo [...] (FERREIRA; PEREIRA, 2007, p. 325).

Aqui é necessário um sucinto resgate da história da teoria do currículo. A expressão 'conteúdo curricular' tem sua origem no modelo americano BILTON, T. et al. Introductory Sociology. 2 ed. Londres: Macmillan, 1987. 
funcionalista de currículo que constituiu a primeira influência no pensamento brasileiro, na década de 1920. Na década de 1980, período de redemocratização no país, as referências marxistas representadas pelos discursos educacionais da pedagogia histórico-crítica e da pedagogia do oprimido fortalecem-se no campo da educação e são marcadamente influenciadas pela literatura inglesa. Até a década de 1990, o pensamento dominante sobre o currículo era o de base psicológica, o qual, ao longo da década, aproxima-se cada vez mais da sociologia, cujos trabalhos tinham como objetivo compreender o currículo como um espaço onde as relações de poder se constituem (LOPES; MACEDO, 2002).

Como consequência da vertente intelectual sociológica, na primeira metade da década de 1990, a maioria dos teóricos se debruçava e escrevia sobre temas de caráter político e defendia que o currículo somente poderia ser compreendido se contextualizado política, econômica e socialmente. Nessa época, alguns objetos de estudo foram: currículo e conhecimento, relações entre conhecimento científico/conhecimento escolar/saber popular e senso comum, relação currículo e processos emancipatórios, a superação do currículo como conteúdo. Havia, nessa década, uma preocupação voltada para conceber o currículo como a construção social do conhecimento, processo a partir do qual todos os/as estudantes passam a ser compreendidos como atores ou agentes ativos na construção do currículo. 0 currículo, então, passa a ser concebido como um espaço educacional dentro do qual a diversidade se manifesta, tem expressão. 0 campo de estudos do currículo, assim, passa a incorporar em seu debate um viés de multirreferencialidade (BURNHAM, 1993), caracterizado pelas múltiplas interpretações advindas de atores e contextos distintos.

A segunda metade dos anos 90 move o debate em direção às questões relativas à sociedade pós-industrial como produtora de bens simbólicos, e todas as vertentes de concepção curricular anteriores se contrapõem à multiplicidade inerente ao contemporâneo, recheado de tendências e orientações, as quais ao se entrecruzarem formam a base para a emergência dos híbridos culturais, que por sua multiplicidade de tendências ${ }^{3}$ provoca uma dificuldade para uma definição consensual do conceito de currículo (LOPES; MACEDO, 2002).

Como resultado de uma história mutante, o campo teórico do currículo que

3 As autoras Lopes e Almeida referidas informam que realizaram um levantamento de trabalhos científicos com o descritor 'currículo' e identificaram 117 tendências, entre as quais, "alfabetização; conhecimento e cultura; inovações curriculares específicas; novas tecnologias e interdisciplinaridade” (LOPES; MACEDO, 2002, p. 17). 
adentra o século XXI constitui um campo intelectual que reflete tanto a complexidade advinda da multirreferencialidade e a polissemia do termo currículo, como a disputa pelo poder entre diferentes grupos teóricos "detentores de determinados capitais social e cultural na área" (LOPES; MACEDO, 2002, p. 17) para provar quem tem a autoridade máxima. Segundo Dussel (2002), a reflexão sobre o currículo híbrido ajuda, assim, a

analisar a complexidade dos processos de produção culturais, políticos e sociais que o configuram, introduzindo novas ideias em um campo cujas perguntas foram, muitas vezes, pobres teórica e tecnicamente (por exemplo, buscando formas teóricas puras 'à prova de professores' ou postulando aplicações simplistas de teorias psicológicas ou sociológicas) (p.57, grifo meu).

Este contexto educacional repleto de ambivalências e pobre em perguntas teóricas e técnicas acerca do currículo, aplicado aos contextos da América Latina 4 e do Brasil, respectivamente continente de 'culturas híbridas' (CANCLINI, 1998) e um país com dimensões continentais repleto de diversidades regionais, locais, de linguagem, de culturas, modos e costumes (SOARES, 2010b), conduz à conclusão de que é urgente a tarefa de refletir sobre um currículo para a diversidade e que (de fato!) respeite e valorize o direito de todos/as à educação. No caso brasileiro, essa urgência se intensifica se se considerar, particularmente, a política de inclusão social e educacional do governo federal, cujo discurso - a partir da posse do Partido dos Trabalhadores - afirma estar comprometido com assegurar os direitos à educação dos grupos vulneráveis, ou seja, de todos/as os 50.545 .050 matriculados nas 192.676 escolas de educação básica espalhadas em território nacional (BRASIL, 2013).

A história mostra que ser oriundo de um grupo social em situação de desvantagem significa crescer e se desenvolver em direção à vida adulta circunscrito em um ciclo de impossibilidades (FERREIRA, 2009a, 2009b) materializado pela falta de oportunidade e acesso aos vários segmentos sociais: familiar, educacional, cultural, social, laboral, econômico, todos valiosos e indispensáveis ao desenvolvimento humano integral. Também significa enfrentar contínuas barreiras ao crescimento e desenvolvimento em direção à vida produtiva e à cidadania, à independência e à autossuficiência. Ao tratar da vulnerabilidade de pessoas com deficiência, grupo social considerado "o mais vulnerável dentre os vulneráveis e o mais pobre dentre os pobres" (UNESCO, 2009; AMERENA; BARON, 2008; WORLD BANK, 2008), Farias (2011) define vulnerabilidade como sendo uma experiência humana

4 A América Latina é a região do mundo que tem a maior desigualdade de renda (CASASSUS, 2007, p. 37). 
que possui um "poder corrosivo [...] sobre a dignidade humana da [Pessoa com Deficiência]-PcD, [uma vez que] a maioria tem sua vida limitada aos espaços familiares e, em alguns casos, tem acesso à primeira etapa da educação básica, etapa escolar onde tendem a permanecer por anos a fio até a vida adulta" (p. 18).

Mas será a desigualdade social e educacional um 'mal perene' sobre o qual não se pode atuar? Será possível à escola contribuir para o combate à desigualdade dentro da qual milhões de crianças e jovens brasileiros estão imersos? O estudo de Juan Casassus (2007), comissionado pela Unesco Orealc ${ }^{5}$, sobre a desigualdade nas escolas revela que

a escola faz diferença na redução dos processos de desigualdade produzidos fora dela. $O$ autor ressalta que, para a América Latina, a escola pode levar à equidade pelos processos que nela se desenvolvem. Porém, ainda segundo o autor, é importante notar que esses mesmos processos, se forem levados a cabo de uma maneira positiva, podem contribuir para uma maior igualdade ou, pelo contrário, se forem levados de maneira inadequada, podem produzir desigualdades. Desta maneira, reflete Casassus, os processos geradores de igualdade, quando operados em sentido negativo, geram desigualdade. Progressivamente, os processos que conduzem à igualdade ou desigualdade vão se transferindo da sociedade para a escola. Há, então, um grupo de fatores, entre os intervenientes no processo de melhor qualificação das populações escolares, que se mostra passivel de ser modificado por escolhas políticas mais adequadas na área educacional (GATTI, 2007, p. 22, grifo meu).

Na mesma linha, ao prefaciar o livro de CASASSUS (2007), Alain Touraine (2007, p. 11) afirma que o estudo conduzido por este sociólogo

demonstra com cifras concretas, analisadas segundo métodos estatísticos sofisticados, que grande parte da desigualdade que se observa na escola e na sua saída é produzida nela mesma e não é herdada das diferenças entre as famílias cujos filhos vão às escolas.

Tais achados revelam, de forma contundente, que há mudanças urgentes a ser implementadas nas redes de ensino no que se refere ao dia a dia da prática pedagógica, didática e curricular, as quais são possíveis, e meu argumento central neste artigo é o de que um currículo comprometido com a valorização da diversidade, o respeito à diferença e a promoção dos direitos humanos constitui um caminho promissor para o desenvolvimento de escolas que produzem cada vez menos injustiça social e iniquidade.

A seguir, conceituo diversidade e discuto sua relação direta com o conceito de diferença. Enfatizo a importância da definição deste conceito como forma de prevenir sua deturpação ao transformar diversidade em diferença individual, em marca identitária que está na base de preconceito, discriminação e exclusão.

5 Orealc - Oficina Regional em Educação para a América Latina e Caribe. 
a identidade é marcada pela diferença, mas parece que algumas diferenças [...] são vistas como mais importantes que outras, especialmente em lugares particulares e em momentos particulares [ou seja, no bojo das relações de poder]. Em outras palavras, a afirmação das identidades nacionais é historicamente específica [...] a emergência dessas diferentes identidades é histórica; ela está localizada em um ponto específico do tempo. Uma das formas pelas quais as identidades estabelecem suas reivindicações é por meio do apelo a antecedentes históricos (SILVA, 2000, p. 11). ${ }^{6}$

ENTENDENDO O CONCEITO DE DIVERSIDADE E DIFERENÇA...

Ao tratar do conceito de diversidade, inevitavelmente devemos abordar o conceito de diferença porque os dois estão intrinsecamente entrelaçados. Também é necessário ter cuidado para não reduzir o conceito de diversidade à diferença humana porque

do ponto de vista cultural, a diversidade pode ser entendida como a construção histórica, cultural e social das diferenças. A construção das diferenças ultrapassa as características biológicas, observáveis a olho nu. As diferenças são também construídas pelos sujeitos sociais ao longo do processo histórico e cultural, nos processos de adaptação do homem e da mulher ao meio social e no contexto das relações de poder. Sendo assim, mesmo os aspectos tipicamente observáveis, que aprendemos a ver como diferentes desde o nosso nascimento, só passaram a ser percebidos dessa forma porque nós, seres humanos e sujeitos sociais, no contexto da cultura, assim os nomeamos e identificamos (GOMES, 2007, p. 17, grifo meu).

Aplicada à vida real, essa definição contribui para que se possam compreender os desdobramentos e implicações de uma concepção reducionista do conceito de diversidade. Por exemplo, reduzir uma criança com Síndrome de Down às características resultantes da trissomia7 do par 21 de cromossomos significa reduzir sua diferença humana ao que é observável e aparente apenas (seus traços ou jeito de falar). Ou seja, significa desconsiderar tudo o mais que torna esta criança um ser humano integral com habilidades, potencialidades, competências, emoções, como qualquer outra pessoa sem a síndrome possui, manifesta socialmente e desenvolve ao longo da vida. Da mesma forma, conceber uma pessoa cega ou surda como incapazes significa circunscrevêla aos limites de sua sensorialidade, ignorando e negligenciando todos os outros sentidos e características que a tornam um ser humano integral.

Não é possível, contudo, negar que a diversidade é também um componente

6 A expressão antecedentes históricos, quando relacionada à pessoa com deficiência, remonta à crença de que a pessoa com deficiência é incapaz e é um problema.

Trissomia do XXI é um distúrbio genético causado pela presença de um cromossomo 21 extra total ou parcial e que causa uma combinação de diferenças maiores ou menores na estrutura corporal, associadas a algumas dificuldades cognitivas e desenvolvimentais. 
do desenvolvimento biológico da humanidade, mas não se restringe a essa dimensão apenas. A dimensão cultural constitui elemento preponderante no processo de construção das concepções acerca do outro/a e de nossa vida de relação com o outro/a que estão presentes em todas as produções sociais, de valores, linguagens e técnicas e não apenas na diferença biológica individual. As diferenças humanas, portanto, não são per se, mas construídas pelo outro, ou seja, por nós, porque todos/as nós - independentemente de classe social, condição econômica, onde vivemos ou o que fazemos -, somos sujeitos sociais que vivemos cotidianamente os processos de adaptação ao meio social e cultural, subjacente aos quais estão presentes relações de poder que subjugam o/a outro/a baseadas em suas diferenças. Como consequência, os valores, crenças e concepções que incorporamos por meio da cultura nos levam a acreditar que nosso distanciamento do (que consideramos ser um) 'problema do outro' é legítimo e serve para justificar nossa ignorância, a qual está na base da violência, do preconceito e da discriminação contra aqueles que acreditamos serem diferentes de nós. Segundo Skliar (2006, p. 23), as diferenças não podem ser concebidas binariamente, isto é,

não podem ser apresentadas, nem descritas em termos de melhor e/ou pior, bem e/ou mal, superior e/ou inferior, positivas e/ou negativas, maioria e/ou minoria, etc. [As diferenças] são simplesmente - porém não simplificadamente -, diferenças. Mas o fato de traduzir algumas dessas diferenças como 'diferentes' - e já não simplesmente como diferenças volta a posicionar essas marcas, essas identidades, esse 'ser diferença' como contrárias, como opostas e negativas à ideia de 'normas', do 'normal' e, então, daquilo que é pensado e fabricado como 'correto', o 'positivo', o 'melhor', etc.

As diferenças que nos constituem como seres humanos iguais, em processo de crescimento e contínuo desenvolvimento em todas as esferas da vida, são transformadas na e pela cultura e transformam em 'diferentes' aqueles/ as que não reconhecemos como iguais por causa de suas diferenças suas marcas identitárias (SILVA, 2000; SILVA, 2009). Por isso, ao tratar dos conceitos de diversidade e diferença há que se considerar a subjetividade e a intersubjetividade que constituem nossa relação com o outro/a porque a diversidade e a diferença que nos caracterizam como iguais não estão ‘lá fora’, desligadas de quem somos, mas aqui, presentes no nosso agora existencial. Entender essa premissa é chave quando o foco de atenção está colocado sobre grupos vulneráveis, uma vez que o enfrentamento de problemas, tais como exclusão, violência e discriminação, implica assumir que o 'problema' que os afeta (o/a outro/a que acreditamos ser diferente de nós por suas marcas identitárias) 'não está lá', mas em cada um que perpetra a violência ou se cala diante da violação de seus direitos garantidos por meio de legislação vigente. 
Mike Oliver (1995), sociólogo inglês, usuário de cadeiras de rodas e ativista, quando define a deficiência como sendo uma 'tragédia pessoal' da pessoa com deficiência, contribui para a reflexão sobre a diversidade humana que é nossa, é comum a todos/as e se transforma na diferença no outro, com a qual não me identifico. Por isso, a tragédia é do outro e eu não assumo a responsabilidade de mudar para acolher ou mesmo compreender sob uma referência distinta da marca identitária deficiência. A comum tendência de distanciamento com relação às pessoas com deficiência ocorre porque acreditamos culturalmente que 'o problema está nela' e 'sua deficiência' (ou diferença individual) é 'algo' de sua exclusiva responsabilidade (e de seus familiares). Ou seja, 'se você tem um problema, o problema é seu - sua tragédia(!) e eu não posso mudar, adaptar ou ajustar atitudes, contextos e espaços para acomodá-la ou apoiála, integrá-la ou incluí-la, acolhê-la ou respeitá-la.

Historicamente, a concepção da 'diferença' como 'diferente' fez com que as pessoas com deficiência fossem isoladas e impedidas de conviver com seus pares (famílias, vizinhos, amigos, colegas de escola). Essa concepção patologizante, estigmatizante e excludente está na base da segregação educacional da pessoa com deficiência, isto é, do modelo médico-patológico da educação em escolas especiais, segregadas do sistema educacional regular (FERREIRA, 2004; 2006; 2009a). O modelo da educação inclusiva, em oposição à educação especial, parte do princípio de que são as atitudes das pessoas sem deficiência que devem mudar, são os espaços que devem se tornar acessíveis, são as formas de comunicação e informação que devem ser plurais e diversificadas para ser acessíveis a todos/as e são as escolas, as metodologias de ensino e os currículos que devem ser transformados para que todos os/as estudantes possam conviver com os colegas e participar das atividades de sala de aula em condições de igualdade (FERREIRA, 2007). No Brasil, a Lei de Acessibilidade (BRASIL, 2004) assegura o direito de a pessoa com deficiência lutar pelo seu direito ao acesso, isto é, seu direito a essas mudanças.

Tanto mundialmente como no Brasil, o movimento da inclusão social e educacional da pessoa com deficiência, desencadeado pela publicação da Declaração de Salamanca (UNESCO, 1994), tem provocado um crescente processo de ruptura com a concepção médico-patológica da deficiência e, como resultado, ao longo de 20 anos, tem gerado rupturas significativas quanto ao entendimento de que essas pessoas devem viver isoladas e segregadas dos ambientes comuns. No mesmo sentido, a inclusão de crianças, jovens e adultos com deficiência nas escolas regulares e nos espaços sociais comuns 
tem propiciado a convivência entre pessoas sem deficiência com pessoas com deficiências e, consequentemente, novas aprendizagens quanto às suas potencialidades humanas, pessoais, profissionais e outras contribuem para a redução das experiências de opressão que afetam suas vidas. Nesse sentido, a meu ver, o movimento pela inclusão social e educacional de pessoas com deficiência tem contribuído de forma determinante para promover o combate e remoção de barreiras (atitudinais, arquitetônicas, comunicacionais, informacionais e pedagógico-curriculares), ao mesmo tempo em que promove os direitos humanos desse grupo social: direito à participação social, educacional, laboral; direito à certidão de nascimento e de viver com sua família, direito ao lazer e à vida amorosa, entre outros.

Embora a maior parte das pessoas com deficiência ainda esteja imersa no que eu denomino como sendo um ciclo de impossibilidades e circunscritas aos limites impostos socialmente, com certeza a aprovação da Convenção dos Direitos da Pessoa com Deficiência pela Organização das Nações Unidas, em 2006 e a ratificação desta pelo governo brasileiro em 2008, constituem elementos-chave na consolidação dessa ruptura e avanço contínuo. Contudo, por mais que se reconheça a diversidade humana como crucial ao processo de humanização, persiste ainda a tendência cultural de ressaltar como positivos e melhores os valores que são próprios da sociedade moderna, isto é, os valores de quem tem o poder econômico, o privilégio social, o poder político (os três Ps!), valores que geram distanciamento, estranhamento e até mesmo uma rejeição em relação ao 'diferente'. Na mesma linha, embora estudos internacionais definam equidade social como a possibilidade de expansão de benefícios adquiridos por alguns grupos sociais privilegiados (como a educação básica) à totalidade das populações, isso não significa - paralela e proporcionalmente - a ampliação das despesas públicas para esse fim. Pelo contrário, "a educação é estendida a todos, mas o gasto público continua o mesmo" (QUILES, s.d., p. 4, grifo meu).

Imersos na política pública de inclusão social e educacional do governo federal para a inclusão dos/as estudantes oriundos de grupos menos favorecidos, os/ as educadores/as brasileiros/as convivem e atuam em um contexto políticoideológico neoliberal que se contradiz no cotidiano escolar: propõe a equidade na educação e viola os direitos de aprender em condições de igualdade com os estudantes das melhores escolas. A escola brasileira e suas comunidades encontram-se, portanto, submersas nas contradições políticas, enquanto simultaneamente procuram sobreviver aos graves problemas estruturais que as afetam, tais como classes superlotadas, falta de recursos pedagógicos, 
professores/as com qualificação falha, ausência de manutenção sistemática de seus prédios e, sobretudo, metodologias de ensino ultrapassadas, isto é, práticas pedagógicas do século XIX para ensinar crianças e jovens do século $\mathrm{XXI}$.

Ao longo de mais de 15 anos, atuando como pesquisadora de estudos conduzidos em escolas brasileiras, em parceria com as comunidades escolares e sempre ouvindo as vozes dos/as estudantes e dos/as docentes, apesar de todas as complexidades e desafios que assolam essa instituição social hoje, desenvolvi uma visão positiva quanto às possibilidades de nosso sistema educacional apresentar sucesso por meio de um currículo para a diversidade e que seja responsivo ao direito de todos/as à educação, o qual entendo como sendo uma possibilidade viável às demandas atuais de melhoria da qualidade em educação e a formação humana.

Cabe aqui ressaltar que minha visão positiva, mas crítica e não ingênua, reflete a escuta e a observação sistemática da ação de educadores e educadoras comprometidos com a criação de melhores oportunidades de desenvolvimento para seus estudantes, a maioria filhos e filhas de grupos sociais menos favorecidos. Professoras e professores, coordenadoras e coordenadores pedagógicas, diretoras e diretores de escolas que, mesmo conscientes das barreiras criadas pelo sucateamento de suas escolas e pela sobrecarga na gestão de 'pilhas de demandas diretas'8 - PDD do MEC, se mantêm na linha de frente para apoiar o desenvolvimento e a formação humana de seus estudantes. As inúmeras ações do MEC provocam um distanciamento da gestão escolar e dos educadores/as quanto às questões pedagógicas, uma vez que são empurrados para realizar contínuas tarefas de gerenciamento para as quais não estão preparados/as, porque os gestores/ as das escolas brasileiras tendem a ser professores/as que assumiram essa função na sua escola. Como forma de aliviar a sobrecarga sobre a tarefa de gestão organizacional de escolas, o MEC lançou o

\footnotetext{
[...] Programa Nacional Escola de Gestores da Educação Básica Pública faz parte das ações do Plano de Desenvolvimento da Educação (PDE) e surgiu da necessidade de se construir processos de gestão escolar compativeis com a proposta e a concepção da qualidade social da educação, baseada nos princípios da moderna administração pública e de modelos avançados de gerenciamento de instituições públicas de ensino, buscando, assim, qualificar os gestores das escolas da educação básica pública, a partir do oferecimento de cursos de formação a distância. A formação dos gestores é feita por uma rede de universidades públicas, parceiras do MEC (BRASIL, MEC, s.d.).
}

Alusão irônica ao Programa Dinheiro Direto na Escola-PDDE ou Plano de Desenvolvimento da Escola-PDE. 
Na primeira seção deste artigo, abordei as mudanças ocorridas no campo da teoria do currículo ao longo de quase cem anos. A partir dessas mudanças, novos conceitos emergiram com o desenvolvimento do conhecimento na área, outros foram resgatados e novos termos foram cunhados em cada período histórico, os quais gradualmente penetraram no universo da educação, influenciando práticas pedagógicas e chegando até o discurso dos educadores/as. Dentre estes, cito como exemplos formação docente, direitos humanos, inclusão, exclusão, diversidade, práticas pedagógicas inovadoras e currículo para a diversidade.

O tema e o conceito de diversidade como discuto neste artigo ganham espaço nesse contexto no final do século XX como consequências das políticas de inclusão de grupos historicamente excluídos da educação. Desde então, vem ganhando no Brasil, em particular, espaço nos debates e produções dos documentos oficiais, assim como estudos científicos. Por exemplo, em 2007, a Secretaria da Educação Básica do Ministério da Educação lançou a Coleção Indagações sobre Currículo, cujo conjunto de cinco documentos foi desenvolvido por acadêmicos de renome - Currículo e desenvolvimento humano; Educandos e educadores: seus direitos e o currículo; Currículo, conhecimento e cultura; Diversidade e currículo e Currículo e avaliação. Essa coleção tem a finalidade de incentivar um debate nacional sobre o currículo, sua função na sociedade brasileira do século XXI e importância para 0 desenvolvimento da melhoria das escolas brasileiras.

De acordo com a visão do $\mathrm{MEC}^{9}$, os autores das indagações sobre o currículo estão em consonância quando consideram que

a educação, o conhecimento, a escola [e] o currículo [devem estar] a serviço de um projeto de sociedade democrática, justa e igualitária. Um ideal de sociedade que avança na cultura política, social e também pedagógica. Uma sociedade regida pelo imperativo ético da garantia dos direitos humanos para todos. Diante do ideal de construir essa sociedade, a escola, o currículo e a docência são obrigados a se indagar e tentar superar toda prática e toda cultura seletiva, excludente, segregadora e classificatória na organização do conhecimento, dos tempos e espaços, dos agrupamentos dos educandos e também na organização do convivio e do trabalho dos educadores e dos educandos. É preciso superar processos de avaliação sentenciadora que impossibilitam que crianças, adolescentes, jovens e adultos sejam respeitados em seu direito a um percurso contínuo de aprendizagem, socialização e desenvolvimento humano (BRASIL, 2007, p. 13-14, grifo meu).

9 Todos os documentos possuem uma seção comum de autoria dos organizadores da Coleção, a qual representa a visão do MEC sobre o que foi produzido pelos convidados comissionados para tal produção. 
Essa citação reforça a concepção de uma sociedade inclusiva que é mais democrática, justa e igualitária para todos/as, na qual é assegurado o direito à educação, esfera de formação crucial para a formação humana, para a formação do sentido de cidadania e para a entrada no mercado de trabalho qualificado. Todavia, o desafio agora está exatamente em garantir o respeito a esse direito assegurando a participação na vida escolar e na aprendizagem, assim como nas outras esferas da vida fundamentais para a formação em geral. Para isso é urgente que, nas escolas, as comunidades sejam conscientizadas sobre seu papel na luta contra a desigualdade, conforme alerta Casassus (2007) em seu estudo, e adquiram conhecimento e competências no sentido de desenvolver estratégias pedagógicas de promoção da superação de "toda prática e toda cultura [e avaliação] seletiva, excludente, segregadora e classificatória na organização do conhecimento" (BRASIL, 2007, p. 11), conforme reafirmado no texto oficial acima citado.

Com este propósito, ao definir na coleção um documento que trata exclusivamente da diversidade na escola, o governo federal lança ao sistema educacional brasileiro uma orientação de reflexão e ação acerca de mudanças indispensáveis para assegurar uma experiência educacional valiosa para suas vidas, uma vez que

a função da escola, da docência e da pedagogia vem se ampliando, à medida que a sociedade e, sobretudo, os educandos mudam e o direito à educação se alarga, incluindo o direito ao conhecimento, às ciências, aos avanços tecnológicos e às novas tecnologias de informação. Mas também o direito à cultura, às artes, à diversidade de linguagens e formas de comunicação, aos sistemas simbólicos e ao sistema de valores que regem o convívio social, a formação como sujeitos (GOMES, 2007, p. 13, grifo meu).

É interessante notar que embora a diretriz seja clara acerca dos objetivos educacionais assumidos no discurso oficial, Nilma Lino Gomes, a autora do caderno Diversidade e currículo, coloca como sua primeira constatação que

de fato, não é tarefa fácil para nós, educadores e educadoras, trabalharmos

pedagogicamente com a diversidade. Mas não será essa afirmativa uma contradição? Como a educação escolar pode se manter distante da diversidade sendo que a mesma se faz presente no cotidiano escolar por meio da presença de professores/as e alunos/as dos mais diferentes pertencimentos étnico-raciais, idades e culturas? (BRASIL, 2007, p. 18, grifo meu).

A meu ver, essa constatação constitui uma tentativa de reforçar a dificuldade na tarefa de educar para a diversidade, enquanto deveria primar pelo chamamento positivo das possibilidades de desenvolvimento de uma ampla população de crianças e jovens que chegaram aos bancos escolares e finalmente(!) têm uma chance de desenvolvimento humano, apesar dos limites impostos pela 
condição socioeconômica na qual nasceram. A questão que o documento deveria colocar não é 'se há ou não há uma contradição' na afirmativa, mas como a presença de professores/as e estudantes com diversos backgrounds pode ser enriquecedora para a comunidade escolar, para a aprendizagem de todos/as e, especialmente, valiosa para um processo de formação humana comprometido com uma sociedade mais igualitária e justa para cada um/a e todos/as.

Ao longo de mais de 30 anos atuando no campo da educação e direito à educação da pessoa com deficiência, o discurso que escuto cotidianamente é o das impossibilidades: a literatura, a TV, as relações sociais, a fala dos educadores e dos acadêmicos e também o discurso oficial, todos/as enfatizam aquilo que não funciona, o que não está bem, o que não é bom, o que é difícil... Quando se trata, por exemplo, do discurso de educadores/as em exercício nas escolas brasileiras e, independentemente da região, o discurso é o da tragédia: "Na escola onde eu trabalho você não imagina como é ruim”. Mas a questão é que todos/as falam isso! Quer dizer, é sempre muito ruim em todos os cantos do país. É sempre uma situação ‘sem chance de mudanças' porque tudo se traduz em uma 'tarefa difícil', como a constatação da autora acima citada. É, portanto, uma visão apocalíptica da escola e das crianças e jovens brasileiros, que não têm hoje, e não terão amanhã, como sair desse ciclo de impossibilidades.

Minha visão e meu argumento de mudanças possíveis, por outro lado, é positiva. Como acadêmica com publicações sistemáticas e convites para participação em eventos dirigidos a educadores/as brasileiros de diferentes regiões do país, tenho clareza acerca de minha responsabilidade social e educacional, mas também do privilégio e poder que um microfone (ou um computador) nas mãos representa. Por isso, adotando um posicionamento distinto, sempre procuro analisar e refletir sobre as questões educacionais desde uma referência positiva, de possibilidades, apesar das barreiras e desafios dentro das quais estão circunscritas. Considero que focar nas 'tarefas difíceis' significa eliminar a esperança e o desejo de realização de uma educação mais significativa para cada criança brasileira porque 0 sentimento de dificuldade a ser enfrentado e de impossibilidade paralisa nossa criatividade.

Ao tratar de um currículo para a diversidade, então, argumento que este deve ser um currículo para os direitos humanos e, considerando-se que os currículos são constituídos por um conjunto de conhecimentos e práticas pedagógicas 
articulados a um tempo e espaço histórico específicos, cujas dinâmicas são reinterpretadas cotidianamente na escola, o currículo da educação básica deste nosso tempo e espaço deve reconhecer a diversidade, promover os direitos humanos e a inclusão de todos/as. Como realizar essa tarefa de forma efetiva? Como incorporar esses elementos na prática pedagógica? Como se desenvolver em direção a uma pedagogia que é de possibilidades para todos/ as, para o desenvolvimento de todos/as da comunidade escolar? Como tornar a escola um espaço de debate e reflexão sobre as experiências constitutivas da vida dos/as estudantes, valorizando-as e buscando caminhos novos para a superação e o enfrentamento de possíveis barreiras?

Ao abordar um currículo para a diversidade e responsivo aos direitos humanos dentro dessa perspectiva positiva, é importante lembrar que, diferentemente de um passado não muito distante, contemporaneamente o currículo não é considerado um conteúdo pronto, completo e rígido. Ou seja, não está dado, não é construído. É exatamente sua incompletude e flexibilidade que permite sua construção pelos inúmeros participantes da comunidade escolar. 0 currículo acontece no tempo e no espaço das vidas e das atividades, na escola e na sala de aula. Da mesma forma, como a educação formal não pode mais ser concebida como uma experiência de ensino e aprendizagem desarticulada e centrada em conhecimentos convencionados como verdadeiros que o docente domina, de cima pra baixo, o currículo não pode mais ser concebido como um ‘conteúdo' que é 'passado para o estudante’ porque - cada vez mais - os/as estudantes, a comunidade escolar e a cultura local fazem parte do processo de construção curricular.

No passado, o currículo era concebido como sendo neutro, de base científicopositivista. No século XX, entretanto, as teorias pós-críticas inserem uma nova concepção de vida, de mundo e de aprendizagem no currículo escolar, à medida que passam a considerar as relações de poder existentes na sociedade. Tal ruptura epistemológica introduz no contexto educacional novos e importantes conceitos, dentre os quais cito: identidade, alteridade, diferença, subjetividade, significação e discurso, relação saber-poder, representação, cultura, gênero, raça, etnia, sexualidade, multiculturalismo, habilidades e necessidades educacionais e, certamente, inúmeras outras que vão emergir ao longo do século XXI com a revolução tecnológica. (Por isso, o novo Plano Nacional de Educação - 2011-2021 incorpora esses termos em seu texto.) O referencial pós-crítico do currículo considera os contextos concretos da vida, isto é, envolve a compreensão das dinâmicas sociais, das dinâmicas políticas e intelectuais e, obviamente, das pedagógicas. Portanto, não atinge 
facilmente consensos entre os teóricos.

Assumindo, então, que a construção de um currículo acontece no espaço, tempo e dinâmicas atuais, no seio de uma sociedade que é, endemicamente, excludente, que não valoriza como relevante a diversidade humana e que discrimina o 'diferente', esta reflexão sobre o currículo conduz a outro universo, qual seja, a contraposição entre a exclusão e a inclusão em educação, cujas tensões não podem ser ignoradas quando defendemos um currículo responsivo aos direitos humanos:

- na inclusão todos e qualquer um, sem distinção, têm direitos e todos são respeitados; na exclusão há violação dos direitos.

- na inclusão comprometemo-nos com a aquisição - as aprendizagens; na exclusão impomos limites, constrangimentos, restrições.

- na inclusão assumimos a importância de mudar para acolher a diferença; na exclusão acreditamos que ser diferente é 'anormal': você não pertence à mesma ‘tribo' do outro.

- na inclusão promovemos a aceitação e a celebração da diversidade humana; na exclusão manifestamos discriminação, preconceito, atos de violência, etc. (barreiras atitudinais).

Essas tensões precisam ser superadas no contexto de um currículo para a diversidade e fundamentadas nos direitos humanos. Defendo que a Pedagogia das Possibilidades constitui um caminho porque se compromete com o desenvolvimento humano e a emancipação de grupos vulneráveis - já que os grupos privilegiados tendem a encontrar naturalmente oportunidades em suas vidas. A emancipação só ocorre em um contexto educacional favorável à aprendizagem política sobre seus direitos e deveres. Desde muito cedo, portanto, o estudante precisa encontrar no espaço escolar oportunidades para desenvolver uma compreensão sobre direitos humanos e seu poder de participação e escolhas. Nesse sentido, uma Pedagogia das Possibilidades forma o sujeito de direito porque favorece processos de empoderamento, “mecanismo pelo qual as pessoas, as organizações, as comunidades tomam controle de seus próprios assuntos, de sua própria vida, de seu destino, tomam consciência de sua habilidade e competência para produzir, gerar e gerir" (COSTA, s/d). Um bom exemplo desse processo diz respeito ao "protagonismo juvenil', que constitui um movimento social de empoderamento de jovens - no caso das pessoas com deficiência, é denominado 'autoadvocacia' (SOARES, 2010a; DANTAS, 2011). Ambos propiciam condições para o empoderamento desses grupos. 
O currículo de uma Pedagogia de Possibilidades, dessa forma, se configura como um currículo de rupturas porque ajuda pessoas de grupos vulneráveis a construir novas formas de ser e estar no mundo, de sentir e interagir com o outro: educa para o respeito à diversidade e ensina a respeitar a diferença no outro; incorpora reflexão sobre os problemas sociais relevantes à formação humana e tudo o mais que for relacionado ao cultivo de nossa humanidade e preservação da nossa civilização.

De acordo com o documento Subsídios para a elaboração de diretrizes gerais da educação em direitos humanos: versão preliminar (SILVEIRA; NADER; DIAS, 2007) os "direitos humanos são nucleados pela concepção de dignidade da pessoa humana" (p. 6) e a universalidade desse princípio ético constitui um "atributo de humanidade, da espécie humana. Em decorrência de tal atribuição, todo ser humano é considerado sujeito de direitos que lhes assegurem a vida como um valor intrínseco". Tornar-se um sujeito de direitos, então, implica necessariamente adquirir uma formação política, ou seja, ao aprender sobre seus direitos, o sujeito, ao mesmo tempo, conscientiza-se sobre sua violação; ao aprender sobre o uso da lei para autoproteção, aprende a proteger o outro/a; ao aprender a adotar uma atitude reflexiva, crítica e questionadora, compromete-se com a justiça social fomentando ações encorajadoras diante de mudanças, conflitos e crises, porque as mesmas aterrorizam muitos/as e trazem turbulência aos ambientes comuns de convivência.

Os processos educativos fundamentados nos direitos humanos "se realizam na necessária autonomia do sujeito do conhecimento, expressão educacional do sujeito de dignidade na diversidade" (SILVEIRA; NADER; DIAS, 2007, p. 8). Portanto, um currículo da Pedagogia das Possibilidades tem uma preocupação com a formação ética dos educandos/as e, ao mesmo tempo, educa e forma para o cultivo do pacto de amor pela humanidade, que é um sentido de pertencimento a uma civilização humana digna. Dessa forma, rompe com a noção errônea de que somos diferentes e de que fazemos parte de grupos sociais distintos.

Todos os elementos constitutivos de um currículo para a diversidade e fundamentado nos direitos humanos necessariamente têm um compromisso inerente com a promoção e defesa da justiça e equidade social. Para tanto, na escola, é necessário assegurar a participação e a representatividade real dos vários segmentos da comunidade no desenvolvimento de projetos pedagógicos, planejamento escolar e planejamento docente sobre o significado de justiça social, tendo em vista conscientizar os/as estudantes 
sobre quem é excluído (quem excluímos?), quem é o sujeito de comentários nocivos, depreciativos, de bullying e por quê. Quem é alvo de discriminação e por quem? Compreender tais elementos que atravessam o cotidiano das relações na escola é condição sine qua non para lutar contra a desigualdade entre grupos baseada na diferença. Ao promover a conscientização sobre crítica destrutiva, a indiferença ou atitude preconceituosa ao outro/a que consideramos 'diferente', e também ao alheamento em relação aos temas socialmente relevantes para todos/as, este currículo para a diversidade desenvolve a compreensão das diferenças, a valorização do 'diferente' como complementar e enriquecedor e forma o 'sujeito de direitos'.

A escola que adota uma Pedagogia das Possibilidades e um currículo para a diversidade fundamentado nos direitos humanos deve adotar em seu projeto pedagógico metodologias de ensino e aprendizagem inovadoras, dinâmicas, agradáveis e que estimulem a interação humana na sala de aula. Isso significa combater as práticas tradicionais e imobilizantes do ficar sentado um atrás do outro, olhando o pescoço do colega e dizendo ‘amém’ ao professor. Alinhada a essa concepção, a docência deve comprometer-se a favorecer e mediar a colaboração e o apoio mútuo entre os/as estudantes, diferenciar os processos de aprendizagem com base nas diferenças, habilidades ou necessidades individuais, assim como os ritmos e estilos de aprendizagem. No século XXI, qualquer currículo não pode prescindir do compromisso com a formação tecnológica dos educandos/as, fundamental ao exercício de sua cidadania produtiva; à formação de redes de aprendizagem e ao compartilhamento de experiências exitosas ou de demandas emergentes no cotidiano escolar, porque a educação é um direito humano e é também “um direito-meio indispensável às sociedades, grupos sociais e indivíduos para a consecução dos demais direitos" (SILVEIRA; NADER; DIAS, 2007, p. 13). Assim, os

Processos educativos devem levar em consideração a(s) cultura(s)/identidade(s) cultural(is) constitutivas dos sujeitos educandos, buscando o entendimento da sua historicidade, sem hierarquização valorativa das suas diferenças, que nada mais é do que uma hierarquização em termos de dignidade. Mediante uma postura compreensiva das diversidades socioculturais, urge propiciar uma aprendizagem de convivência na tolerância, no que significa bem comum aos sujeitos e grupos que compõem as coletividades sociais.

Em sociedades profundamente assimétricas, como a brasileira, da perspectiva de suas várias diferenças socioculturais, não se construirão concepções e práticas de bem comum, se não houver uma sociedade/educação a par do respeito à diversidade, ao mesmo tempo, para a tolerância entre diferentes e a solidariedade entre desiguais, especialmente para aqueles em condições socioeconômicas e culturais de subalternidade, que quase não lhes permitem saírem da situação de assujeitados para o patamar de sujeitos de direitos (SILVEIRA; 


\section{'Pedagogy of Possibilities': is it possible to have one single curriculum for the diversity we found in Brazilian schools?}

Abstract: This paper focuses on answering the question: is it possible a curriculum for diversity and responsive to the rights of all to education? For this purpose, and considering a context of educational exclusion and inclusion of vulnerable groups, first the paper adresses social inequalityu in a historical perspective in order to caracterizing the foundation of beliefs that generate victimation of the other based on his/her difference. Latin America and Brasil data shows the severe educational inequality between groups. The history of curriculum is, then, presented in order to show how this a soil for dispute filled with controversies and disagreement. Secondly, the concepto of diversity is presented as well as its direct correlation with the concept of difference. The relevance of this concept is enphasided as a means to prevent its misunderstanding that turns diversity into individual difference, an indentity mark that is at the basis of exclusion. Finally, a reflection on a curriculum for diversity and for the rights of all to education by means of a Pedagogy of Possibilities. With this paper I hope to contribute to the debate that focuses on the moving on from the current education system culture of valuing impossibilities too ne that values good practices and pedagogy.

Keywords: Currículum. Diversity. Difference. Human rights. Pedagogy of Possibilities. 


\section{REFERÊNCIAS}

AMERENA, P.; BARON, Tanya (Eds.). Disability and Development. Leonard Cheshire International, 2008.

BRASIL. Indagações sobre currículo. BEAUCHAMP, Jeanete; PAGEL, Sandra Denise; RIBEIRO, Aricélia do Nascimento (Orgs.). Brasília: Ministério da Educação, Secretaria de Educação Básica, 2007. 48 p.

Constituição Federal. Lei de Acessibilidade. Decreto-Lei nํㅗ 5.296, de 2 de dezembro de 2004 .

BRASIL/INEP. Educacenso - Censo Escolar da Educação Básica 2012. Brasília: Instituto Nacional de Estudos e Pesquisas Educacionais Anísio Teixeira, 2013. Disponível em:〈portal.inep.gov.br/basica-censo〉. Acesso em: 5 mar. 2014.

BRASIL/MEC. Programa Nacional Escola de Gestores da Educação Básica. Ministério da Educação. Portal do MEC. s/d Disponível em: 〈http://portal.mec. gov.br/index.php?option=com_content\&id=12337\&ltemid=693〉. Acesso em: 8 abr. 2014.

BURNHAM, T. Complexidade, multirreferencialidade, subjetividade: três referências polêmicas para a compreensão do currículo escolar. Em Aberto, Brasília, v. 12, n. 58, p. 3-13, abr./jun. 1993.

CANCLINI, Nestor Garcia. Culturas híbridas-estratégias para entrar e sair da modernidade. São Paulo: Edusp, 1998.

CARVALHO, Maria Eulina Pessoa de; ANDRADE, Fernando Cézar Bezerra de; MENEZES, Cristiane Souza de (Orgs.). Equidade de gênero e diversidade sexual na escola: por que uma prática pedagógica inclusiva? Escolas Plurais. Projeto Iguais porque Diferentes. João Pessoa: Editora Universitária UFPB, 2009. 45 p.

CASASSUS, Juan. A escola e a desigualdade. 2. ed. Brasília: Unesco; Liber Livros. 2007. 201 p.

COSTA, Alice. Gênero, Poder e Empoderamento das Mulheres. s/d. Disponível em:〈http://www.agende.org.br/docs/File/dados_pesquisas/feminismo/ Empoderamento\%20-\%20Ana\%20Alice.pdf〉. Acesso: 05 Maio 2014.

DANTAS, Taisa Caldas. Jovens com deficiência como sujeitos de direito: o exercício da autoadvocacia como caminho para o empoderamento e a 
participação social. João Pessoa, 2011. Dissertação (Mestrado em Educação) - Programa de Pós-Graduação em Educação, Universidade Federal da Paraíba, Universidade Federal da Paraíba.

DELORS, Jacques. Educação: um tesouro a descobrir. Relatório para a Unesco da Comissão Internacional sobre a Educação para o Século XXI. 4. ed. Brasília: Unesco; Ministério da Educação; Cortez Editora, 2000.

DUSSEL, Inês. O currículo híbrido: domesticação ou pluralização das diferenças? In: LOPES, Alice Casimiro; MACEDO, Elizabeth (Orgs.). Currículo: debates contemporâneos. São Paulo: Cortez, 2002, p. 55-77. (Série Cultura, Memória e Currículo, v. 2).

FARIAS, Adenize de Queiroz. Gênero e deficiência: vulnerabilidade feminina, ruptura e superação. João Pessoa, 2011. Dissertação (Mestrado em Educação) - Programa de Pós-Graduação em Educação, Universidade Federal da Paraíba.

FERREIRA, Windyz Brazão. Entendendo a discriminação contra estudantes com deficiência na escola. In: FÁVERO, Osmar; FERREIRA, Windyz; IRELAND, Timothy; BARREIROS, Débora. (Orgs.). Tornar a educação inclusiva. Brasil: Unesco, 2009a, p. 11-53. Disponível em: 〈http://unesdoc.unesco.org/ images/0018/001846/184683POR.pdf \. Acesso em: 10 jan. 2014.

- EJA \& deficiência: estudo da oferta da modalidade EJA para estudantes com deficiência. In: AGUIAR, Marcia Angela da S. Educação de Jovens e Adultos. 0 que dizem as pesquisas? Recife: Secretaria de Educação Continuada, Alfabetização e Diversidade-Secad/MEC; Associação Nacional de Pesquisa em Educação-Anped; Universidade Federal de Pernambuco, 2009b, p. 75-128. Disponível em: 〈http://www.ufpe.br/cead/eja/textos/dizem_as_ pesquisas_1.pdf〉. Acesso: 20 abr. 2014.

- Inclusão e exclusão no Brasil: reflexões sobre a formação docente dez anos após Salamanca. In: RODRIGUES, David. (Org.) Inclusão e educação: doze olhares sobre a educação inclusiva. São Paulo: Summus, 2006, p. 211238.

. Invisibilidade, crenças e rótulos: reflexão sobre a profecia do fracasso educacional na vida de jovens com deficiência. In: CONGRESSO BRASILEIRO SOBRE SÍNDROME DE DOWN FAMÍLIA, AGENTE DA INCLUSÃO, 4., 2004, Salvador. Anais... Salvador: Federação da Síndrome de Down, 2004. 
. Making sense of exclusion in schools: an international perspective. Tese submetida à Faculdade de Educação para obtenção do título de Ph.D. (Doctor of Philosophy). Inglaterra: University of Manchester, 2001. 343 p.

; MARTINS, Regina Coeli Braga. De docente para docente: práticas de ensino e diversidade para a educação básica. São Paulo: Summus, 2007.

; PEREIRA, Maria de Lourdes. Seminários Temáticos de Prática Curricular na Educação Infantil. Trilha do Aprendente, n. 2, 2007.

FOUCAULT, Michel. The Use of Pleasure. The History of Sexuality. Nova York: Vintage Books, 1990.

GATTI, Bernardette A. Prefácio à edição brasileira. In: CASASSUS, Juan. A escola e a desigualdade. 2. ed. Brasília: Unesco; Liber Livros, 2007.

GIDDENS, Antony. Sociology. 2. ed. Oxford: Blackwell Publishers/Polity Press, 1993.

GOMES, Nilma Lino. Indagações sobre currículo: diversidade e currículo. In: BEAUCHAMP, Jeanete; PAGEL, Sandra Denise; RIBEIRO, Aricélia do Nascimento (Orgs.). Indagações sobre currículo. Brasília: Ministério da Educação, Secretaria de Educação Básica, 2007.

LOPES, Alice Casimiro; MACEDO, Elizabeth. O pensamento curricular no Brasil. In: (Orgs.). Currículo: debates contemporâneos. São Paulo: Cortez, 2002, p. 13-54. (Série Cultura, Memória e Currículo, v. 2).

OLIVER, Michael. Does special education have a role to play in the twenty-first century? Reach Journal of Special Needs Education, Irlanda, v. 8, n. 2, p. 67-76, 1995.

QUILES, Raquel Elizabeth Saes. Políticas públicas em educação especial pós94: alguns apontamentos sobre o conceito de surdez. Universidade Federal do Mato Grosso do Sul, s.d. Disponível em: 〈http://www.histedbr.fae.unicamp. br/acer_histedbr/jornada/jornada7/_GT2\%20PDF/POL\%CDTICAS\%20 P\%DABLICAS\%20EM\%20EDUCA\%C7\%C30\%20ESPECIAL\%20P\%D3S\%20 1994\%20ALGUNS.pdf〉. Acesso em: 15 maio 2013.

REICH, Robert B. Why the rich are getting richer and the poor are getting poorer. In: HALSEY, A. H.; LAUDER, Hugh; BROWN, Phillip; WELLS, Amy Stuart. Education: Culture, Economy and Society. Oxford: University Oxford; New York, p. 156-171, 1997. 
RIVERO, José. Educação e exclusão na América Latina: reformas em tempos de globalização. Brasília: Universa, 2000. 342 p.

SILVA, Rodrigo Correia da. Empoderamento e participação juvenil. In: Juventude, mobilização social e saúde: interlocuções com políticas públicas. Recife: Movimento de Adolescentes do Brasil; Instituto Papai; Canto Jovem; 2009. Disponível em: 〈http://www.unfpa.org.br/Arquivos/ena.pdf〉. Acesso em: 2 abr. 2014.

SILVA, Tomaz Tadeu. Documentos de identidade: uma introdução às teorias do currículo. Belo Horizonte: Autêntica, 1999. 145 p.

; HALL, Stuart; WOODWARD, Kathryn (Orgs.). Identidade e diferença: a perspectiva dos estudos culturais. Petrópolis: Vozes, 2000.

SILVEIRA, Rosa Maria Godoy; NADER, Alexandra Antonio Gili; DIAS, Adelaide Alves. Subsídios para a elaboração de diretrizes gerais da educação em direitos humanos: versão preliminar. João Pessoa: Editora Universitária-UFPB, 2007. 34 p.

SKLIAR, Carlos. A inclusão que é "nossa" e a diferença que é do "outro". In: RODRIGUES, David (Org.). Inclusão e educação: doze olhares sobre a educação inclusiva. São Paulo: Summus, 2006. 318 p.

SOARES, Alessandra Mendes Miranda. Nada sobre nós sem nós. Estudo sobre a formação de jovens com deficiência para o exercício da autoadvocacia. João Pessoa, 2010. Dissertação (Mestrado em Educação) - Programa de PósGraduação em Educação da Universidade Federal da Paraíba. 2010b.

SOARES, Márcia Torres Nery. Programa Educação Inclusiva Direito à Diversidade: Estudo de caso sobre estratégia de multiplicação de políticas públicas. João Pessoa, 2010. Dissertação (Mestrado em Educação) - Programa de Pós-Graduação em Educação da Universidade Federal da Paraíba. 2010a.

TAYLOR, P. et al. Education (Chapter 8). In: TAYLOR, P. et al. Sociology in Focus. Lancs: CPL/Causeway Press, 1997. p. 273-308.

TOURAINE, Alain. Prefácio à segunda edição. In: CASASSUS, Juan. A escola e a desigualdade. 2. ed. Brasília: Unesco; Liber Livros, 2007. 201 p.

UNESCO. Policy Guideline on Inclusion in Education. Paris: Unesco, 2009. Disponível em: 〈http://unesdoc.unesco.org/images/0017/001778/177849e. pdf〉. Acesso: 15 mar. 2014. 
UNESCO. Declaração de Salamanca. Sobre princípios, políticas e práticas na área das necessidades educativas especiais, 1994. Disponível em: 〈http:// www.portal.mec.gov.br/seesp». Acesso em: 15 mar. 2014.

WORLD BANK. Disability and poverty, a survey of the World Bank Poverty assessments and implications. Discussion Paper n. 0805, fev. 2008. Disponível em: 〈http://siteresources.worldbank.org/DISABILITY/ Resources/280658-1172608138489/WBPovertyAssessments.pdf〉. Acesso em: 03 mar. 2014.

RECEBIDO: Fevereiro de 2014.

APROVADO: Março de 2014. 